\title{
Investors' Risk Preference Characteristics and Conditional Skewness
}

\author{
Fenghua Wen, Zhifang He, and Xiaohong Chen \\ School of Business, Central South University, Changsha, Hunan 410083, China \\ Correspondence should be addressed to Xiaohong Chen; csu_cxh@163.com
}

Received 6 November 2013; Accepted 22 December 2013; Published 16 January 2014

Academic Editor: Jianping Li

Copyright (C) 2014 Fenghua Wen et al. This is an open access article distributed under the Creative Commons Attribution License, which permits unrestricted use, distribution, and reproduction in any medium, provided the original work is properly cited.

Perspective on behavioral finance, we take a new look at the characteristics of investors' risk preference, building the D-GARCHM model, DR-GARCH-M model, and GARCHC-M model to investigate their changes with states of gain and loss and values of return together with other time-varying characteristics of investors' risk preference. Based on a full description of risk preference characteristic, we develop a GARCHCS-M model to study its effect on the return skewness. The top ten market value stock composite indexes from Global Stock Exchange in 2012 are adopted to make the empirical analysis. The results show that investors are risk aversion when they gain and risk seeking when they lose, which effectively explains the inconsistent risk-return relationship. Moreover, the degree of risk aversion rises with the increasing gain and that of risk seeking improves with the increasing losses. Meanwhile, we find that investors' inherent risk preference in most countries displays risk seeking, and their current risk preference is influenced by last period's risk preference and disturbances. At last, investors' risk preferences affect the conditional skewness; specifically, their risk aversion makes return skewness reduce, while risk seeking makes the skewness increase.

\section{Introduction}

Risk preference refers to the attitude people hold towards risks, which is a key factor in studies on investors' decisionmaking behavior. Standard financial theory assumes that investors are rational and believes that when making investment decisions they tend to have invariant risk preferencesrisk averse. However, as the research goes, people gradually find that the investors' decision-making behavior in real life does not always comply with the assumption of rationality and their behaviors are usually limited by their own cognitive biases and external environment, leading to their risk preferences varying with different situations.

With the development of behavioral finance, a multitude of research indicated that the result of investment in the financial market can affect their decisions, making them exhibit inconsistent risk preference. Prospect Theory proposed by Kahneman and Tversky [1] had described some prominent psychological traits of investors in their decisionmaking under uncertainty. Their experiments suggested that individuals tend to be risk averse with gain and risk seeking with loss, which have been confirmed by a variety of subsequent studies. For example, Laughhunn and Payne [2] found evidence that 20 managers in the process of their multiple risk choice performed risk averse for gains and risk seeking for losses; Fernandes and Luiz [3] discovered that participants in his experiment were less willing to take risks after getting gains and were more willing to take risk after obtaining losses. Similar viewpoints were expressed by other authors $[4,5]$. Some scholars even argued that the value of return also exerted effect on investors' risk preference. The ANSTGARCH-M model proposed by Anderson et al. [6] assumed that investors' risk preference was related to the value of return, and the empirical study suggested that the degree of people's risk aversion changed with their return. Thaler and Johnson [7] made an experiment and found that investors' risk preferences depended on the psychological value of return, and a similar finding was reached elsewhere $[8,9]$. Brunnermeier and Nagel's [10] research demonstrated that investors' risk preferences changed with their wealth. Besides, Chou et al. [11] argued that investors' required compensation for risk varied with the compensation of last period, which meant that investors' current attitude towards risk is influenced by their attitudes in the last period. Anderson's et al. [6] study implied that people's current risk compensation 
was influenced by last period's residual errors. Studies as discussed in $[12,13]$ believed that investors' degree of risk aversion varied with time. Thus we believe that investors' risk preference is time-varying with the influence of the states of gain and loss, the value of return, and some other factors, such as last period's risk preference and last period's residual errors.

On the other hand, a large number of studies showed that the return distributions of financial assets always showed deviation from normal distribution with negative or positive. The original explanation of skew distribution of the return is based on the asymmetric impact of volatility. Christie [14] and French et al. [15] did some early research in this field, but their explanations had not been widely supported by empirical study. Ekholm and Pasternack [16] proposed a negative news threshold hypothesis, ascribing skewed return distribution to the different disclosure policies of positive and negative news. Empirical evidence of Bae et al. [17] indicated that the distribution of return skewness would change with different corporate governance performances. These studies about the cause of skewed distribution were made mainly from macroscopic perspective, while with the development of behavioral financial theory, an increasing number of scholars came to consider the impact of investors' risk preference and behavioral biases on the skewness of return distribution from microscopic perspective.

For example, Harvey and Siddique [18] believed that investors' inclination to sell losing shares and hold gaining ones would result in negative return skewness. Bakshi et al. [19] revealed that investors' risk aversion contributed a lot to the negative skewness. Wen et al. [20] confirmed that return distributions were influenced by people's behavior biases, holding the view that overconfidence and regret aversion were two common psychological biases among investors, which would result in negative skewed distribution of return. Post's et al. [21] study discovered that people's risk aversion would decrease the skewness premium coefficient. Wen and Yang [22] believed that risk preference was an important reason for the skewed distribution, and the speculative behaviors in stock market can lead to positive skewness. All these studies suggested that risk preference did have a role in skewed return distribution.

Based on the above studies, this paper maintains that investors' risk preference is, on the one hand, time-varying under the influences of the states of gain and loss, the value of return, and other factors (last period's risk preference and disturbance). On the other hand, it is a main cause of skewed return distribution. Most previous studies about risk preference based on the Behavioral Finance Theory were done through psychology experiments and with the help of individual transaction accounts. However, real market scenes can hardly be simulated through experiment, and personal transaction accounts are usually hard to access and not adequately represented. Therefore, this paper takes the behavior of the whole stock market as the research object and uses composite index data in stock market from Global Stock Exchanges to make the study. It begins with a thorough analysis and a full description of investors' risk preference and then further investigates the effect of risk preference on the conditional skewness. This paper is organized as follows.
Section 2 presents the model analysis; Section 3 provides empirical study; robustness test is presented in Section 4, and Section 5 concludes the paper.

\section{Model Analysis}

Risk preference must first be measured effectively when studying its characteristics. Risk aversion is manifested by a preference for sure gains rather than equivalent uncertainty gains. If the expected returns for uncertain gains increase, investors' preference may be reversed, which means that only when sufficient compensation is provided, can investors be incentivized to accept the uncertain gains. In other words, investors show more inclination to risk averse if they demand more risk compensation. Analogically, risk seeking is manifested in a contrary way. Therefore certainty equivalent, which refers to the minimum returns that investors request for uncertain gains, could be used to measure risk preference. This can be explained by returns from risk investment, from which subtract the riskless returns, we can get risk premiums. Risk premiums are people's compensations for taking risks. A high risk premium means a high risk compensation required by investors for taking risk, which reflects risk aversion. While if investors are willing to take risks at the cost of some returns, in which case the risk premium is negative, in this situation people are risk seeking.

In GARCH-M model, the risk premium coefficient in the mean equation represents the required compensation for each unit of risk. The larger the risk premium coefficient is, the greater the compensation required by investors is, the stronger the tendency is to be risk averse. Therefore, the risk premium coefficient can be used to measure investors risk preference. Wen and Yang [22] indicated that the coefficient $\gamma$ in GARCH-M model, namely, the risk premium coefficient, can be used to characterize investors' risk preference. In this paper, investors' risk preference is also measured by the risk premium coefficient. The GARCH-M model is expressed as follows:

$$
\begin{gathered}
r_{t}=c+\gamma \sqrt{h_{t}}+\varepsilon_{t}, \\
\varepsilon_{t}=\sqrt{h_{t}} \eta_{t}, \\
h_{t}=\alpha_{0}+\alpha_{1} \varepsilon_{t-1}^{2}+\alpha_{2} h_{t-1},
\end{gathered}
$$

where the daily stock return is $r_{t}=100 * \ln \left(p_{t} / p_{t-1}\right), h_{t}$ is the conditional variance, $\alpha_{0}>0, \alpha \geq 0, \beta \geq 0$, and $\alpha+\beta<1$ guarantee the stationarity of return process; the risk premium coefficient $\gamma$ is the parameter measuring investors' preference; $\gamma>0$ means investors require more risk compensation with increasing risks; thus to make investors take certain risks, enough compensations should be provided, which denotes that investors are risk averse. $\gamma<0$ means that the risk compensation demanded by investors reduces with increasing risks and they are willing to lose certain interests to take some risks, which suggests that investors like pursuing risk and are risk seeking. $\gamma=0$ means that investors' expected returns are not sensitive to the risk that they are taking and the risk does not affect the size of their expected return, 
so investors are risk-neutral. Therefore, the different sign of parameter $\gamma$ reflects people's different risk preference.

In short, the study on investors' risk preference characteristics is on the basis of the GARCH-M model. It mainly includes three parts: firstly, a distinction between state of gain and lose is made to study the change of risk preference caused by different states of gain and loss; secondly, the effect of the value of return on risk preference is considered; thirdly, a comprehensive characterization is made to further examine the effects of other factors on risk preference.

2.1. Risk Preferences and States of Gain and Loss. In GARCH$\mathrm{M}$ model, the risk premium coefficient $\gamma$ remains constant, which means that the compensation required by investors for each unit of risk is fixed. However, according to behavioral financial theory, investors make different decisions and have different risk preference when getting gains and losses, which means that the coefficient $\gamma$ varies with the state of gain and loss. So this paper holds that investors' states of gain and loss can produce great influence on their risk preference.

In addition, the parameter $\gamma$ in GARCH-M model is widely used in most previous studies on the risk-return relation. A number of studies [23-25] corroborated that risk in stock markets are significantly positively related to returns. However, an agreement was not reached among scholars as to the positive relationship between risk and return. Brandt and Kang [26], Ang et al. [27], and Bali et al. [28] show a significantly negative risk-return relation. Yet there were also some studies [29-31] that even find that no significant correlation exists between risk and return.

Many scholars attempted to explain the conflicting empirical evidence with different methods. For instance, Lanne and Saikkonen [32] and Lanne and Luoto [33] in American stock markets emphasized that only when the constant term in the mean equation was set to zero, can risk and return be in positive correlation. Kanas [34] contended that different distributions of the error term (such as the normal distribution, the Student's $t$-distribution, and the Generalized Error Distribution (GED)) play an important part in determining whether the relationship between returns and risks is positive or negative. Christensen et al. [35] concluded that only in financial crisis could a significantly positive correlation be detected between risk and return, while in normal times there was no clear relation. According to Prospect Theory, investors are risk averse for gains and risk seeking for losses, which means that states of gain and loss will affect investors' attitudes towards risks. So the risk premium coefficient will be different with gain and loss. As a consequence, investors' different attitudes toward gains and losses will affect the relationship between risk and return. Investors are risk seeking when losing, resulting in a negative risk premium coefficient, and risk averse when gaining, representing a positive risk premium coefficient. We believe that this is an important cause for the existence of both positive and negative relation between risk and return.

Therefore, we take traditional GARCH-M model as basic model and introduce two indicate variables which are used to make a distinction between states of gain and loss to reflect the change of investors' risk preference. We call it D-GARCH$M$ model and it is specified as

$$
\begin{gathered}
r_{t}=c+\gamma \sqrt{h_{t}}+\varepsilon_{t}, \\
\gamma=\gamma_{1} \cdot D u_{t}+\gamma_{2} \cdot D d_{t}, \\
\varepsilon_{t}=\sqrt{h_{t}} \eta_{t}, \\
h_{t}=\alpha_{0}+\alpha_{1} \varepsilon_{t-1}^{2}+\alpha_{2} h_{t-1} .
\end{gathered}
$$

$D u_{t}$ and $D d_{t}$ are indicator variables for gains and losses, respectively, and their definitions are as follows:

$$
\begin{aligned}
& D u_{t}= \begin{cases}1, & p_{t}-r p_{t}>0, \\
0, & p_{t}-r p_{t} \leq 0,\end{cases} \\
& D d_{t}= \begin{cases}0, & p_{t}-r p_{t}>0, \\
1, & p_{t}-r p_{t} \leq 0,\end{cases}
\end{aligned}
$$

where $p_{t}$ is the stock price at time $t$ and $r p_{t}$ represents investors' reference price at time $t$. When the stock price is higher than reference price, it means investors in gain state, and loss state otherwise. Parameter $\gamma_{1}$ is the required compensation for each unit of risk when gaining and $\gamma_{2}$ is the required risk compensation for each unit of risk when losing. Their symbols reflect investors' risk preference in gain and loss. According to the Prospect Theory, $\gamma_{1}$ is supposed to be greater than 0 , and $\gamma_{2}$ is supposed to be lesser than 0 ; namely, investors are risk averse for gains and are risk seeking for losses.

It should be pointed out that the reference price is a critical factor to the judgments of gains and losses. If the stock price exceeds the reference price, investors get gains or otherwise obtain losses. Reference price, as a kind of investors' psychological price, is subjectively determined, and there is no final conclusion at present for a reasonable reference price. Many researches select the average price as reference prices. For example, studies in $[36,37]$ pointed out that compared with specific details, people are more likely to remember the general information; namely, people usually focus more on the average and tend to ignore the details of things. Lev [38] confirmed that the enterprise normally takes the industry average performance level as a reference point to adjust their performance level. And Frecka and Lee [39] use different data to get the same conclusion. Grinblatt and Han [40] chose the weighed average price over the past five years as investors' decision-making reference price. Considering that a lot of latest information in stock market can exert great influence on investors' decisionmaking behavior, the reference price adopted by investors will be dynamic. Meanwhile, full consideration should also be given to people's practical operations during the process of investment when choosing reference price. And the moving average, as an important indicator of stock price movement trend, plays a great role in the technical analysis of securities and usually it is a decisive factor for investors' stock trading. Investors tend to make decisions by analyzing these trend lines (5-day, 10-day, 20-day, and 30-day average line). Among 
all these trend lines, investors focus more on the average trend of 5 days. Therefore, the 5-day average trend is chosen as reference price in this paper to determine investors' gains and losses. The reference price is estimated as

$$
r p_{t}=\frac{\left(p_{t}+p_{t-1}+p_{t-2}+p_{t-3}+p_{t-4}\right)}{5}
$$

where $p_{t-1}, p_{t-2}, p_{t-3}, p_{t-4}$ are the stork price at period $t-$ $1, t-2, t-3, t-4$, respectively.

2.2. Risk Preference and the Value of Return. With the development of theoretical and empirical research on the effects of gains and losses on risk preference, some scholars realized that such effects also have something to do with the value of return. Prelec and Loewenstein [41] proposed the "Peanuts Effect," maintaining that the degree of risk aversion reduced with the decreasing return. Hopfensitz [42] studied how the current gains and losses affected people's future decision-making, revealing that smaller gains would reduce future investment and bigger gains would increase future investment. It implied that smaller gains would result in a decrease of risk seeking, while bigger returns would increase the degree of risk seeking. And vice versa for losses, that is, smaller losses increased investments and bigger losses decreased investment, which implied that smaller losses would lead investors to seek risk, while bigger losses would decrease the degree of risk seeking. All these evidences indicated that the value of return would affect investors' risk preference. O'Connell and Teo [43] concluded that the extent of risk seeking of institutional investors tend to improve with increasing return. The research results of Genesove and Mayer [44] indicated that there were less selling behaviors when people experience a larger amount of loss, which meant that investors are inclined to hold stocks and become risk seeking for losses. Therefore, we further investigate how the magnitude of current return affects investors' risk compensation.

According to behavioral finance, investors determine the gain and loss by comparing the stock price with the reference price. When estimating the value of return, reference price should also be taken into consideration. Therefore we argue that the part of the stock price that exceeds the reference price, that is, $\left(p_{t}-r p_{t}\right)\left(p_{t}\right.$ and $r p_{t}$ are the stock price and the reference price), is the value of gain. And the part of the stock price below the reference price is the value of loss. We define the value of gains and losses by considering the preference price which is usually involved in people's decision-making process, so it is more in line with reality. As a result, $p_{t}-r p_{t}$ which presents the value of gains or losses can be used to measure the value of return that influence people's risk preference. $p_{t}-r p_{t}$ is the absolute size. Based on the return formula $r_{t}=100 *\left(p_{t}-p_{t-1}\right) / p_{t-1}$, we estimate the magnitude of return that affects risk preference also using the relative size, which is defined as $d r_{t}=\left(p_{t}-r p_{t}\right) / r p_{t}$, where $d r_{t}$ is called the reference return. When calculating return, we multiply the data by 100 , so the reference return is also multiplied by 100 to get $d r_{t}=100 *\left(p_{t}-r p_{t}\right) / r p_{t}$. In light of the above analysis investors' risk preference is different with gain and loss, so the reference return is also divided into positive and negative reference return, which are used to indicate the value of gain and loss that affect investors' risk preference. And the prior D-GARCH-M model can be extended into the following form, which is called DRGARCH-M model:

$$
\begin{gathered}
r_{t}=c+\gamma \sqrt{h_{t}}+\varepsilon_{t} \\
\gamma=\gamma_{1} \cdot d r_{t} \cdot D u_{t}+\gamma_{2} \cdot\left(-d r_{t}\right) \cdot D d_{t} \\
\varepsilon_{t}=\sqrt{h_{t}} \eta_{t} \\
h_{t}=\alpha_{0}+\alpha_{1} \varepsilon_{t-1}^{2}+\alpha_{2} h_{t-1},
\end{gathered}
$$

where $d r_{t} \cdot D u_{t}$ stands for the positive reference return and $\left(-d r_{t}\right) \cdot D u_{t}$ stands for the negative reference return. Parameter $\gamma_{1}$ reflects investors demanding compensation for each unit of risk when obtaining each unit of gain. $\gamma_{1} \cdot d r_{t}$ describes the required compensation varying with the value of gains. Similarly, $\gamma_{2}$ represents the compensation investors demanded for each unit of risk when obtaining each unit of loss, and $\gamma_{2} \cdot\left(-d r_{t}\right)$ illustrates that the required compensation changes with losses for each unit of risk. What is more, the sign of $\gamma_{1}$ and $\gamma_{2}$ can reflect people's different preferences. Just as we explained in model (1), the positive $\gamma_{1}$ means that investors are risk averse, while the negative $\gamma_{2}$ means that people are risk seeking.

2.3. Other Characteristics of Risk Preference. After investigating the influence of investor's current magnitude of return on risk preference, this paper will further study other factors that possibly affect investor's risk preference. Firstly, as a market participant facing various risks in the market, the investor must have the capacity to tolerate certain degree of risk; that is to say, every investor has the intrinsically invariant potential to speculate. Secondly, human being's behavior always exhibits certain continuity and current behavior is more or less affected by previous behavior, and speculative behavior may, to some extent, find its root in prior behavior. Thirdly, the traditional financial theory indicates that people usually unavoidably weigh the return and risk when making relevant policy, so it is essential to consider the effect of risk factors. Lastly, according to the research of Anderson et al. [6], people's risk tolerance changes with time as it is influenced by the last period's disturbance. Those factors jointly determine investors' risk preference. In view of the above discussion and to further verify those factors that can influence investors' risk preference, this paper, on the basis of DR-GARCH-M model, presents the following GARCHC$M$ model (GARCH-M model with compensation) that can 
fully depict the time-varying characteristics of investor's risk preference:

$$
\begin{gathered}
r_{t}=c+\gamma_{t} \sqrt{h_{t}}+\varepsilon_{t}, \\
\gamma_{t}=\lambda_{0}+\lambda_{1} \gamma_{t-1}+\lambda_{2} \frac{\varepsilon_{t-1}}{\sqrt{h_{t-1}}}+\lambda_{3} \cdot d r_{t} \cdot D u_{t} \\
+\lambda_{4} \cdot\left(-d r_{t}\right) \cdot D d_{t}, \\
\varepsilon_{t}=\sqrt{h_{t}} \eta_{t}, \\
h_{t}=\alpha_{0}+\alpha_{1} \varepsilon_{t-1}^{2}+\alpha_{2} h_{t-1} .
\end{gathered}
$$

Here, $\lambda_{0}$ is the basic risk premium demanded by investors, which can be understood as investors' inherent risk preference for a certain period of time; $\lambda_{1}$ means that the current risk tolerance can be more or less jointly influenced by the last period; $\varepsilon_{t-1} / \sqrt{h_{t-1}}$ is the last period's perturbing information after being adjusted by the risk; $\lambda_{2}$ means the impact of the last period's adjusted disturbance on the compensation. Just as $\gamma_{1} \cdot d r_{t}$ and $\gamma_{2} \cdot\left(-d r_{t}\right)$ in DR-GARCH-M model, $\lambda_{3} \cdot d r_{t}$ is the risk compensation with gain, which shows that investors' risk preference changes with the magnitude of gain; $\lambda_{4} \cdot\left(-d r_{t}\right)$ also indicates that investor s' risk preference varies with the magnitude of loss. However, there is something different between $\gamma_{1}, \gamma_{2}$ and $\lambda_{3}, \lambda_{4}$. That is, the sign of $\gamma_{1}$ and $\gamma_{2}$ in DR-GARCH-M model can reflect people's different risk preferences, while that of $\lambda_{3}$ and $\lambda_{4}$ in GARCHC-M model cannot present people's varying risk preference. The main reason for this is that the GARCHC-M model has investigated other factors that can influence investors' risk preferences, so $\lambda_{3}, \lambda_{4}$ cannot represent the overall risk preference. Therefore, in order to inspect people's different risk preference, we should study the sign of $\gamma_{t}$ which can describe different risk preference.

2.4. The Effect of Risk Preference on Conditional Skewness. Harvey and Siddique [18], based on a noncentral $t$ distribution, characterized the time variation of the variance and the skewness simultaneously using a simple autoregressive conditional skewness model-GARCHS $(1,1,1)$ (GARCH with Skewness):

$$
\begin{gathered}
r_{t}=\varphi^{\prime} z_{t-1}+\varepsilon_{t}, \quad \varepsilon_{t} \mid \Omega_{t-1} \sim N\left(v_{t}, \delta_{t}\right), \\
h_{t}=\alpha_{0}+\alpha_{1} \varepsilon_{t-1}^{2}+\alpha_{2} h_{t-1}, \\
s_{t}=\beta_{0}+\beta_{1} \varepsilon_{t-1}^{3}+\beta_{2} s_{t-1}
\end{gathered}
$$

where $r_{t}$ is the dependent variable which usually refers to the return of stocks; $\varphi^{\prime} z_{t-1}$ stands for the expected price or return; $z_{t}$ is the dummy variable of the complete information set $\Omega_{t}$; the residual error $\varepsilon_{t}$ is assumed a noncentral $t$-distribution $N\left(v_{t}, \delta_{t}\right) ; h_{t}$ and $s_{t}$ are the conditional variance and skewness; and both are varying with time. At the same time, we need to impose the constraints that $0<\alpha_{1}<1,0<\alpha_{2}<1 ;-1<\beta_{1}<$ $1,-1<\beta_{2}<1 ; \alpha_{1}+\alpha_{2}<1,-1<\beta_{1}+\beta_{2}<1$.
To explore the effect of investor's risk preference on the conditional skewness, the time-varying risk premium coefficient $\gamma_{t}$ in GARCHC-M model is introduced into the skew equation in GARCHS-M model, which is called GARCHCS$\mathrm{M}$ model (GARCH-M model with compensation and skewness):

$$
\begin{gathered}
r_{t}=c+\gamma_{t} \sqrt{h_{t}}+\varepsilon_{t}, \quad \varepsilon_{t} \mid \Omega_{t-1} \sim N\left(v_{t}, \delta_{t}\right), \\
\gamma_{t}=\lambda_{0}+\lambda_{1} \gamma_{t-1}+\lambda_{2} \frac{\varepsilon_{t-1}}{\sqrt{h_{t-1}}}+\lambda_{3} \cdot d r_{t} \cdot D u_{t} \\
+\lambda_{4}\left(-d r_{t}\right) \cdot D d_{t}, \\
\ln h_{t}=\alpha_{0}+\alpha_{1} \varepsilon_{t-1}^{2}+\alpha_{2} h_{t-1}, \\
s_{t}=\beta_{0}+\beta_{1} \varepsilon_{t-1}^{3}+\beta_{2} s_{t-1}+\beta_{3} \gamma_{t},
\end{gathered}
$$

where the parameter $\beta_{3}$ denotes the effect of risk preference on conditional skewness. If $\beta_{3}<0$, it means that the size of return skewness will be reduced in the case where investors are risk averse $\left(\gamma_{t}>0\right)$. Instead, if investors are risk seeking $\left(\gamma_{t}<0\right)$, the size of return skewness will be increased. According to the conclusion of Wen et al. [20, 40], the coefficient of risk compensation was negatively correlated with the skewness, and $\beta_{3}$ should be under zero.

In GARCHCS-M model, the conditional noncentral $t$ is so complicated that it causes much difficulty in model estimation. León et al. [45] estimated the autoregressive conditional variance, skewness, and kurtosis model using the GramCharlier series expansion of the normal density function. Then, Xu [46] estimated the parameters for GARCHS model using Gram-Charlier series expansion of the normal density function and truncating at the third moment. With the available information set $\Omega_{t-1}$, the approximate expression of the conditional density function of the standardized error $\eta_{t}=\varepsilon_{t} h_{t}^{-1 / 2}$ can be obtained:

$$
\begin{aligned}
g\left(\eta_{t} \mid \Omega_{t-1}\right) & =\frac{1}{\sqrt{2 \pi}} e^{-\left(\eta_{t}^{2} / 2\right)}\left(1+\frac{s_{t}^{*}}{3 !}\left(\eta_{t}^{3}-3 \eta_{t}\right)\right) \\
& =\phi\left(\eta_{t}\right) \psi^{2}\left(\eta_{t}\right),
\end{aligned}
$$

where $s_{t}^{*}$ denotes the conditional skewness of $\eta_{t}, \phi\left(\eta_{t}\right)$ is the probability density function of the standardized normal distribution, and $(1 / \sqrt{2 \pi}) e^{-\left(\eta_{t}^{2} / 2\right)} ; \psi\left(\eta_{t}\right)$ is the polynomial part at the third moment. As $\eta_{t}=\varepsilon_{t} h_{t}^{1 / 2}$, there is $s_{t}=$ $E_{t-1}\left(\varepsilon_{t}^{3}\right)=s_{t}^{*} h_{t}^{3 / 2}$. Considering that $g\left(\eta_{t} \mid \Omega_{t-1}\right)$ may be negative and the integral of $g\left(\eta_{t} \mid \Omega_{t-1}\right)$ in the definition domain may not equal 1, León et al. [45] made some modification to $g\left(\eta_{t} \mid \Omega_{t-1}\right)$ with the method put forward by Gallant and got the following conditional density function:

$$
\begin{aligned}
f\left(\eta_{t} \mid \Omega_{t-1}\right) & =\frac{\phi\left(\eta_{t}\right) \psi^{2}\left(\eta_{t}\right)}{\Gamma_{t}} \\
& =\frac{(1 / \sqrt{2 \pi}) e^{-\left(\eta_{t}^{2} / 2\right)}\left(1+\left(s_{t}^{*} / 3 !\right)\left(\eta_{t}^{3}-3 \eta_{t}\right)\right)^{2}}{\Gamma_{t}},
\end{aligned}
$$


TABLE 1: Descriptive statistics of returns.

\begin{tabular}{|c|c|c|c|c|c|c|}
\hline Statistic/index & Mean & Std. dev. & Skewness & Kurtosis & JB statistic & ADF test \\
\hline NYSE & 0.011092 & 1.417882 & -0.319853 & 11.71722 & 8072.841 & -54.66 \\
\hline NASDAQ & 0.020059 & 1.540381 & -0.073165 & 7.778844 & 2405.885 & -54.16 \\
\hline N225 & -0.005840 & 1.574768 & -0.519431 & 10.91186 & 6553.403 & -51.26 \\
\hline FTSE & 0.003464 & 1.331208 & -0.118303 & 9.447372 & 4410.472 & -24.43 \\
\hline HSI & 0.025817 & 1.624365 & 0.055671 & 11.81611 & 7984.151 & -50.69 \\
\hline SSE & 0.014062 & 1.702013 & -0.181743 & 6.516299 & 1263.707 & -48.98 \\
\hline TSX & 0.018383 & 1.227107 & -0.627351 & 12.55346 & 9504.789 & -51.87 \\
\hline DAX & 0.010606 & 1.641213 & 0.065995 & 7.537473 & 2206.568 & -51.76 \\
\hline AORD & 0.009815 & 1.069175 & -0.532882 & 8.904713 & 3831.159 & -51.75 \\
\hline BSE & 0.062190 & 1.645750 & -0.066960 & 10.60485 & 6011.757 & -46.49 \\
\hline
\end{tabular}

where $\Gamma_{t}=1+\left(s_{t}^{*} / 3\right.$ !) is the modified term of Gram-Charlier series expansion. Therefore, the modified logarithm of the likelihood function is given by

$$
\begin{aligned}
\mathrm{SLF}^{\prime}= & -\frac{1}{2}(T-1) \times \ln (2 \pi)-\frac{1}{2} \sum_{t=2}^{T} \ln h_{t} \\
& -\frac{1}{2} \sum_{t=2}^{T} \eta_{t}^{2}+\sum_{t=2}^{T} \ln \left(\psi^{2}\left(\eta_{t}\right)\right)-\sum_{t=2}^{T} \ln \left(\Gamma_{t}\right) .
\end{aligned}
$$

A maximum solution to the sample likelihood function (11) can offer a consistent estimation of each parameter.

\section{Demonstration and Result Analysis}

3.1. The Sample and Statistical Characteristic. In this paper, stock markets whose market values are the top 10 in 2012 Global Stock Exchange are chosen with their composite indexes as the sample (the ranking of market value is from the World Federation of Exchanges. Data of NYSE Euronext Europe, the top 5, can not be accessed and is replaced by the top 11, BSE), including NYSE (US), NASDAQ (US), N225 (Japan), FTSE 100 (UK), SSE (China), HIS (Hong Kong, China), TSX (Canada), DAX (Germany), AORD (Australia), and BSE30 (India). The data are obtained from RESSET database and the time span is from March 1, 2002, to March 30,2012 . The basic statistics of the daily return of the above indexes are presented in Table 1.

Table 1 displays summary statistics for the daily returns and it can be found that the return has a quite small mean and is negatively skewned and slightly leptokurtic. The J-B statistics show that all the return series of the above indices are not normal distribution. Besides, the ADF test suggests that all the return series are stationary; therefore GARCH models can be used to make the study.

\subsection{Estimation Results}

3.2.1. Risk Preference Varies with States of Gain and Loss. We first make a research on the relationship between risk and return using GARHC-M model, then go on to investigate the change of the risk preference under investors' different states (gain/loss) with the D-GARCH-M model designed in this paper, and finally make a comparison with results of the two models. Since previous empirical results are very sensitive to the constant term in conditional mean equation and the conditional distribution of error term. So we also show the results of GARHC-M model and D-GARCH-M model both with and without constant term as well as the error term in different distribution, which are shown in Tables 2 and 3. All models shown in the paper are estimated by quasi-maximum likelihood.

Table 2 presents the result of GARCH-M model in different specifications. We find that no matter what the error term is in normal distribution, $t$-distribution, or GED, the parameter $\gamma$ fails to achieve statistical significance across almost all of the stock indexes when the constant term is included in the mean equation, while for those without the constant, the parameter $\gamma$ is strongly statistically significant and positive. It is clear from the table that in GARCH$M$ model, the constant term indeed has great effect on the relationship between risk and return. And only the constant is restricted to zero can the two in positive correlation, in which condition the required compensation of investors increases with the raise of risk, indicating that investors are risk averse. Comparing the values of AIC in alternative distribution, it can be found that the AIC in normal distribution is the largest, and in $t$-distribution and the GED the AIC is close to each other. Relatively speaking, AIC in GED is smaller, indicating that error term in GED of GARCH-M model performs well.

According to behavioral finance theory, investors' attitude towards risk in the state of gain is not the same as that in the state of loss, which means that investors' risk preference is sensitive with states of gains and losses. So we estimate the D-GARCH-M model to examine investors' risk preference under the two opposite positions. Meanwhile, the inclusion or not of the constant term and the error term in different distribution also has attracted considerable attention and the results are shown in Table 3.

In Table 3 , there exist $\gamma_{1}>0$ and $\gamma_{2}<0$ in all alternative distributions (normal distribution, $t$-distribution, and GED). That is, investors demand increasing compensation for each unit of risk when obtaining gain, which means that investors are risk averse in the state of gain, whereas in loss position, the risk compensation they required is less than zero, which 
TABLE 2: Estimation of GARCH-M model.

\begin{tabular}{|c|c|c|c|c|c|c|c|}
\hline \multirow{2}{*}{ Index } & & \multicolumn{2}{|c|}{ Normal distribution } & \multicolumn{2}{|c|}{$t$-distribution } & \multicolumn{2}{|c|}{ GED } \\
\hline & & Constant & Without constant & Constant & Without constant & Constant & Without constant \\
\hline \multirow{3}{*}{ NYSE } & $c$ & 0.037285 & & 0.056926 & & 0.053053 & \\
\hline & $\gamma$ & 0.020119 & $0.058766^{* * *}$ & 0.018008 & $0.077375^{* * *}$ & 0.028549 & $0.084370^{* * *}$ \\
\hline & AIC & 2.962919 & 2.962369 & 2.938076 & 2.937919 & 2.932556 & 2.932365 \\
\hline \multirow{3}{*}{ NASDAQ } & $c$ & 0.016146 & & 0.072376 & & 0.084165 & \\
\hline & $\gamma$ & 0.046555 & $0.060165^{* * *}$ & 0.007275 & $0.068447^{* * *}$ & 0.002899 & $0.073577^{* * *}$ \\
\hline & AIC & 3.319350 & 3.318580 & 3.306540 & 3.306225 & 3.303382 & 3.303241 \\
\hline \multirow{3}{*}{ N225 } & $c$ & 0.076892 & & 0.073078 & & 0.064316 & \\
\hline & $\gamma$ & -0.017186 & $0.043225^{*}$ & -0.008435 & $0.048990^{* *}$ & -0.003133 & $0.047402^{* *}$ \\
\hline & AIC & 3.423548 & 3.423122 & 3.414239 & 3.413779 & 3.413865 & 3.413332 \\
\hline \multirow{3}{*}{ FTSE } & $c$ & -0.014292 & & 0.005377 & & 0.006610 & \\
\hline & $\gamma$ & 0.073075 & $0.057784^{* * *}$ & 0.057634 & $0.063381^{* * *}$ & 0.054986 & $0.062014^{* * *}$ \\
\hline & AIC & 2.906469 & 2.905726 & 2.897869 & 2.897088 & 2.897558 & 2.896780 \\
\hline \multirow{3}{*}{ HSI } & $c$ & 0.022283 & & 0.047106 & & 0.029604 & \\
\hline & $\gamma$ & 0.036816 & $0.055336^{* *}$ & 0.017404 & $0.056604^{* * *}$ & 0.031699 & $0.056770^{* * *}$ \\
\hline & AIC & 3.348514 & 3.347746 & 3.333033 & 3.332403 & 3.324469 & 3.323757 \\
\hline \multirow{3}{*}{ SSE } & $c$ & -0.135642 & & $-0.215324^{* *}$ & & $-0.027019^{* *}$ & \\
\hline & $\gamma$ & 0.106098 & 0.014673 & $0.166742^{* *}$ & 0.023714 & $0.188891^{* * *}$ & $0.034810^{* *}$ \\
\hline & AIC & 3.704455 & 3.7043427 & 3.649145 & 3.650241 & 3.641250 & 3.642729 \\
\hline \multirow{3}{*}{ TSX } & $c$ & 0.057309 & & 0.059409 & & 0.041188 & \\
\hline & $\gamma$ & 0.000389 & $0.065233^{* *}$ & 0.017977 & $0.085432^{* * *}$ & 0.037378 & $0.084175^{* * *}$ \\
\hline & AIC & 2.731783 & 2.731448 & 2.718224 & 2.717943 & 2.717611 & 2.717059 \\
\hline \multirow{3}{*}{ DAX } & $c$ & 0.051921 & & $0.097155^{*}$ & & $0.102690^{*}$ & \\
\hline & $\gamma$ & 0.028379 & $0.071643^{* * *}$ & -0.006136 & $0.075022^{* * *}$ & -0.008491 & $0.077571^{* * *}$ \\
\hline & AIC & 3.385518 & 3.385027 & 3.369126 & 3.369411 & 3.364090 & 3.364545 \\
\hline \multirow{3}{*}{ AORD } & $c$ & 0.054596 & & $0.062207^{*}$ & & $0.064180^{*}$ & \\
\hline & $\gamma$ & 0.004603 & $0.074526^{* * *}$ & 0.001614 & $0.081537^{* * *}$ & -0.002353 & $0.080462^{* * *}$ \\
\hline & AIC & 2.515191 & 2.515343 & 2.503685 & 2.504171 & 2.505476 & 2.506050 \\
\hline \multirow{3}{*}{ BSE } & $c$ & 0.100193 & & 0.118117 & & 0.121229 & \\
\hline & $\gamma$ & 0.015818 & $0.091436^{* * *}$ & 0.016732 & $0.105678^{* * *}$ & 0.012551 & $0.103813^{* * *}$ \\
\hline & AIC & 3.493576 & 3.493396 & 3.467548 & 3.467595 & 3.475211 & 3.475306 \\
\hline
\end{tabular}

Note: ${ }^{* * *},{ }^{* *}$, and ${ }^{*}$ in all tables denote that the parameter is significant at $1 \%, 5 \%$, and $10 \%$ level, respectively.

indicates that investors are risk seeking in the state of loss. It also effectively explains the phenomenon that the risk-return relation between risk and return is inconsistent. Specifically, investors are risk averse when gaining, reflecting a positive correlation between risk and return, while risk seeking when losing, implying a negative risk-return relationship. However, what is different from GARCH-M model is that no matter there exists constant term or not, in the D-GARCH-M model, parameter $\gamma_{1}$ is significantly positive, while $\gamma_{2}$ is significantly negative; for GARCH-M model, only the constant term is excluded can the risk premium coefficient $\gamma$ significantly be positive, and when the constant term is considered, there is no significant relationship between risk and return. This verifies that the result of D-GARCH-M model in this paper is not affected by the constant term.

The AIC in Table 3 suggests the D-GARCH-M model in $t$-distribution perform best for the value of AIC in $t$ distribution is the smallest, which is different from GARCH$\mathrm{M}$ model, in which values of AIC in $t$-distribution and GED are close. In addition, since the constant terms in the mean equations are almost insignificant, the following study will remove the constant terms and use $t$-distribution to do the estimation.

3.2.2. Risk Preference Varies with the Value of Return. According to the above analysis, we adopt reference return to represent investors' value of return and divide the reference return into gains (the positive reference return) and losses (the negative reference return) to measure the magnitude of the gains and losses to further study their influence on investors risk preference, which is expressed in the DRGARCH-M model and the results are shown in Table 4.

As expected, risk premium parameters $\gamma_{1}>0$ and $\gamma_{2}<0$ in Table 4 also indicate that investors are risk averse for gains and risk seeking for losses, which is consistent with the finding in D-GARCH-M model. Moreover, the more gains (positive reference returns) the investors get, the stronger their tendency to be risk aversion is (the larger 
TABLE 3: Results of D-GARCH-M model.

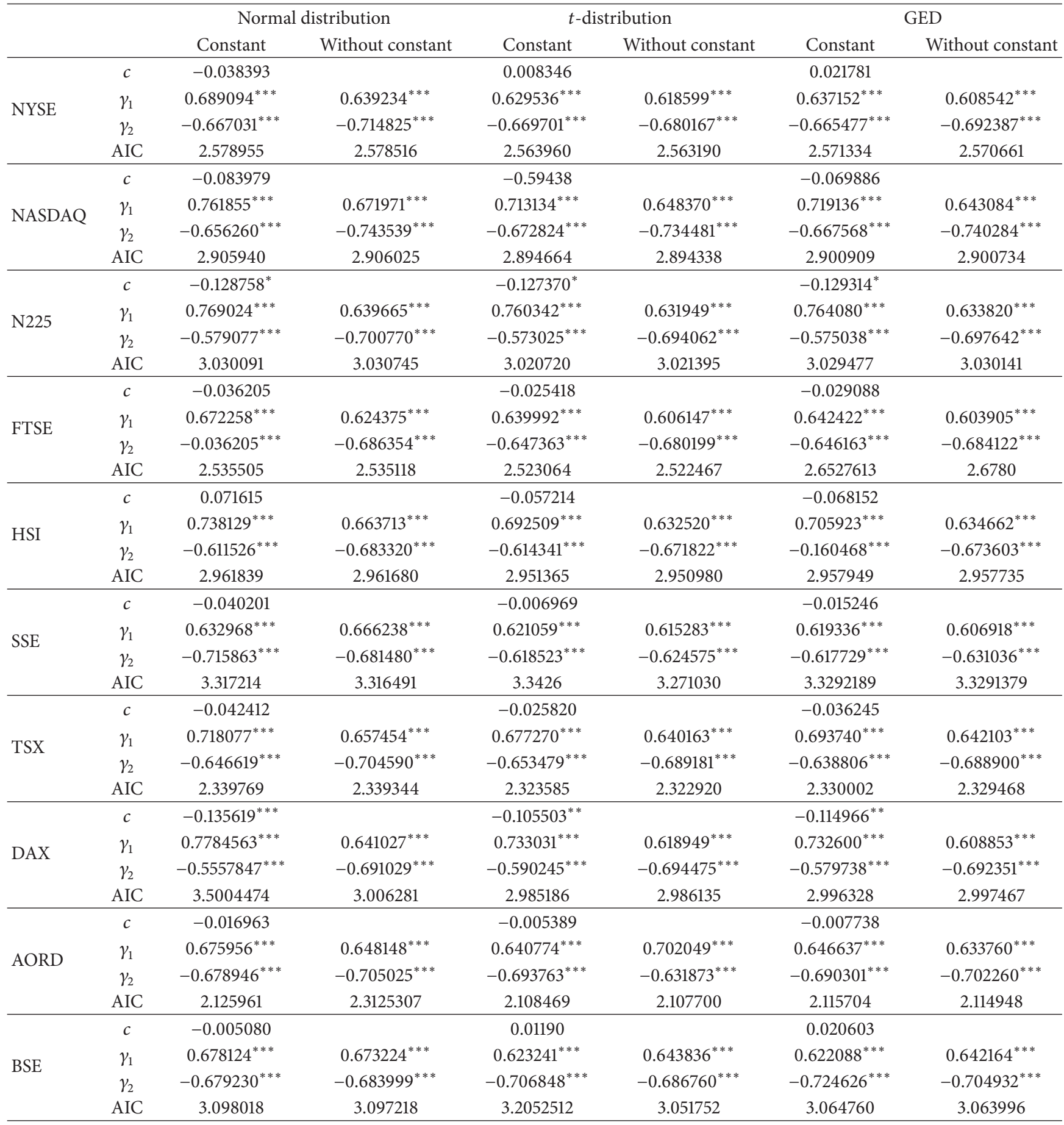

Note: $^{* * *},{ }^{* *}$, and ${ }^{*}$ in all tables denote that the parameter is significant at $1 \%, 5 \%$, and $10 \%$ level, respectively.

the value of $\gamma_{1} \cdot d r_{t}$ is). In the same way, the more losses (the negative reference returns) investors obtain, the stronger their tendency to be risk seeking is (the larger the value of $\left|\gamma_{2} \cdot\left(-d r_{t}\right)\right|$ is). In short, the degree of risk aversion is positively related to the magnitude of gains and that of risk seeking is also positively related to the magnitude of losses.
3.2.3. Other Time-Varying Characteristics of Risk Preference. To fully capture investors risk preference characteristics, based on the DR-GARCH-M model, this paper further studies other factors that may influence investors' risk preference. According to previous analysis, we take into account the effects of investors' inherent risk preference, their last period's 
TABLE 4: Results of DR-GARCH-M model.

\begin{tabular}{|c|c|c|c|c|c|}
\hline & $\alpha_{0}$ & $\alpha_{1}$ & $\alpha_{2}$ & $\gamma_{1}$ & $\gamma_{2}$ \\
\hline NYSE & $0.004863^{* * *}$ & $0.000835^{\text {*** }}$ & $0.995358^{* * *}$ & $0.176024^{* * *}$ & $-0.183713^{* * *}$ \\
\hline NASDAQ & $0.008353^{* * *}$ & $0.001850^{* * *}$ & $0.991113^{* * *}$ & $0.182455^{* * *}$ & $-0.169589^{* * *}$ \\
\hline N225 & $0.007001^{* * *}$ & $0.000195^{* * *}$ & $0.994703^{* * *}$ & $0.197345^{* * *}$ & $-0.164486^{* * *}$ \\
\hline FTSE & $0.008434^{* * *}$ & $0.002253^{* * *}$ & $0.989768^{* * *}$ & $0.206437^{* * *}$ & $-0206568^{* * *}$ \\
\hline HSI & $0.008146^{* * *}$ & $0.000240^{* * *}$ & $0.995920^{* * *}$ & $0.112691^{* * *}$ & $-0.147049^{* * *}$ \\
\hline SSE & $0.069721^{* * *}$ & $0.008750^{* * *}$ & $0.947175^{* * *}$ & $0.124421^{* * *}$ & $-0.138171^{* * *}$ \\
\hline TSX & $0.008868^{* * *}$ & $0.001049^{* * *}$ & $0.988730^{* * *}$ & $0.264073^{* * *}$ & $-0.232588^{* * *}$ \\
\hline DAX & $0.010541^{* * *}$ & $0.011792^{* * *}$ & $0.979174^{* * *}$ & $0.099482^{* * *}$ & $-0.106390^{* * *}$ \\
\hline AORD & $0.004831^{* * *}$ & $0.001204^{* * *}$ & $0.992250^{* * *}$ & $0.295013^{* * *}$ & $-0.282309^{* * *}$ \\
\hline BSE & $0.064522^{* * *}$ & $0.001574^{* * *}$ & $0.961596^{* * *}$ & $0.141245^{* * *}$ & $-0.135208^{* * *}$ \\
\hline
\end{tabular}

Note: ${ }^{* * *},{ }^{* *}$, and ${ }^{*}$ in all tables denote that the parameter is significant at $1 \%, 5 \%$, and $10 \%$ level, respectively.

TABLE 5: Results of GARCHC-M model.

\begin{tabular}{|c|c|c|c|c|c|}
\hline & NYSE & NASDAQ & N225 & FTSE & HSI \\
\hline$\alpha_{0}$ & $0.084414^{* * *}$ & $0.191481^{* * *}$ & $0.164810^{* * *}$ & $0.120755^{* * *}$ & $0.187113^{* * *}$ \\
\hline$\alpha_{1}$ & $0.003259^{* * *}$ & $0.004080^{* * *}$ & $0.001314^{* * *}$ & $0.005550^{* * *}$ & $0.001797^{* *}$ \\
\hline$\alpha_{2}$ & $0.664648^{* * *}$ & 0.274933 & $0.359251^{* * *}$ & $0.455811^{* * *}$ & $0.359104^{* * *}$ \\
\hline$\lambda_{0}$ & 0.249544 & $-0.960250^{* * *}$ & $-5.658753^{* * *}$ & $-1.849845^{* * *}$ & $1.416945^{* * *}$ \\
\hline$\lambda_{1}$ & $-0.546778^{* * *}$ & $-0.550612^{* * *}$ & $-0.555833^{* * *}$ & $-0.547329^{* * *}$ & $-0.559414^{* * *}$ \\
\hline$\lambda_{2}$ & $0.437737^{* * *}$ & $0.435880^{* * *}$ & $0.431086^{* * *}$ & $0.447240^{* * *}$ & $0.429331^{* * *}$ \\
\hline$\lambda_{3}$ & $2.205582^{* * *}$ & $2.141485^{* * *}$ & $2.135520^{* * *}$ & $2.366444^{* * *}$ & $1.994762^{* * *}$ \\
\hline \multirow[t]{2}{*}{$\lambda_{4}$} & $-2.261350^{* * *}$ & $-2.207073^{* * *}$ & $-2.220519^{* * *}$ & $0.543125^{* * *}$ & $-2.056662^{* * *}$ \\
\hline & SSE & TSX & DAX & AORD & BSE \\
\hline$\alpha_{0}$ & $0.221803^{* * *}$ & $0.035956^{* * *}$ & 0.159329 & $0.086445^{* * *}$ & 0.062277 \\
\hline$\alpha_{1}$ & $0.003672^{* * *}$ & $-0.002633^{* * *}$ & 0.003555 & $0.006877^{* * *}$ & 0.001711 \\
\hline$\alpha_{2}$ & $0.334297^{* *}$ & $0.977622^{* * *}$ & $0.553324^{* *}$ & $0.395960^{* * *}$ & 0.978317 \\
\hline$\lambda_{0}$ & $3.271172^{* * *}$ & $-0.946364^{* * *}$ & $-1.498679^{* * *}$ & $-3.876728^{* * *}$ & $-1.142603^{* * *}$ \\
\hline$\lambda_{1}$ & $-0.555094^{* * *}$ & $-0.552272^{* * *}$ & $-0.554922^{* * *}$ & $-0.553163^{* * *}$ & $-0.564773^{* * *}$ \\
\hline$\lambda_{2}$ & $0.434658^{* * *}$ & $0.451861^{* * *}$ & $0.426420^{* * *}$ & $0.425256^{* * *}$ & $0.410996^{* * *}$ \\
\hline$\lambda_{3}$ & $1.872646^{* * *}$ & $0.871728^{* * *}$ & $1.808479^{* * *}$ & $2.900512^{* * *}$ & $0.627976^{* * *}$ \\
\hline$\lambda_{4}$ & $-1.956778^{* * *}$ & $-0.891631^{* * *}$ & $-1.889709^{* * *}$ & $-2.950840^{* * *}$ & $-0.643418^{* * *}$ \\
\hline
\end{tabular}

risk preference, and the last period's disturbance as well as the magnitude of gains and losses obtained by investors to analyze their effects on investors' risk preference. In GARCHC-M model, the effects of these factors on investors' risk preference are expressed, respectively, by $\lambda_{0}, \lambda_{1}, \lambda_{2}, \lambda_{3}$, and $\lambda_{4}$. Results of GARCHC-M model are shown in Table 5.

According to Table 5, parameter $\lambda_{0}$ is almost negative except SSE and HIS ( $\lambda_{0}$ for NYSE is positive but not significant). That is because the stock trading itself is a kind of risk investment and the investors who have entered the stock markets usually have accepted a certain degree of risk and hope to get profits through taking risk. Therefore, their inherent risk preference is risk seeking. Relatively speaking, it is less likely for those highly risk aversion investors to enter the stock market. However, the coefficients $\lambda_{0}$ for SSE and HIS are significantly positive, which indicates that Chinese investors in stock market are inherently risk averse. And it may due to some limitations of the Chinese stock market (such as the government interference, short-sale constraints, and the imperfect information disclosure system), so Chinese ordinary investors are always in such a weak position to get information that they become more cautious when deciding to enter the stock market. $\lambda_{1}$ is significantly negative in each index, denoting that investors' risk aversion may reverse. Namely, the more risk aversion the investors display in the last periods, the more likely their degree of risk aversion will be lowered in the current period.

All $\lambda_{2}$ are significantly positive, which means that if the previous disturbance is positive $\left(\varepsilon_{t-1}>0\right)$, the stock price will rise in response to previous favorable news and investors will gain in the current period. At that point, investors may believe that the previous favorable news has been almost reflected in the stock price in the current period, so that in the next period the response of the stock price to the last period's information will be weak, and it is less likely for stock price to rise. At the same time, investors tend to be more risk averse because of their gain in the current period; on the contrary, if there was unfavorable news $\left(\varepsilon_{t-1}<0\right)$ in 
TABLE 6: Results of GARCHCS-M model.

\begin{tabular}{|c|c|c|c|c|c|}
\hline & NYSE & NASDAQ & $\mathrm{N} 225$ & FTSE & HSI \\
\hline$\alpha_{0}$ & $0.032748^{* * *}$ & $0.059882^{* * *}$ & $0.109288^{* * *}$ & $0.065898^{* * *}$ & $0.054940^{* * *}$ \\
\hline$\alpha_{1}$ & $0.003755^{* * *}$ & $0.011491^{* * *}$ & $0.004289^{* * *}$ & $0.003981^{* * *}$ & $0.004468^{* * *}$ \\
\hline$\alpha_{2}$ & $0.840223^{* * *}$ & $0.761472^{* * *}$ & $0.571782^{* * *}$ & $0.597459^{* * *}$ & $0.831583^{* * *}$ \\
\hline$\lambda_{0}$ & 0.520869 & $-1.818666^{* * *}$ & $-5.558346^{* * *}$ & $-1.669158^{* *}$ & $1.498100^{* * *}$ \\
\hline$\lambda_{1}$ & $-0.534450^{* * *}$ & $-0.554154^{* * *}$ & $-0.549442^{* * *}$ & $-0.545990^{* * *}$ & $-0.564360^{* * *}$ \\
\hline$\lambda_{2}$ & $0.389653^{* * *}$ & $0.405554^{* * *}$ & $0.425541^{* * *}$ & $0.436965^{* * *}$ & $0.382486^{* * *}$ \\
\hline$\lambda_{3}$ & $2.427590^{* * *}$ & $2.103677^{* * *}$ & $2.141823^{* * *}$ & $2.717860^{* * *}$ & $1.723770^{* * *}$ \\
\hline$\lambda_{4}$ & $-2.417871^{* * *}$ & $-2.111141^{* * *}$ & $-2.240880^{* * *}$ & $-2.804423^{* * *}$ & $-1.918894^{* * *}$ \\
\hline$\beta_{0}$ & $0.011167^{* * *}$ & $0.034400^{* * *}$ & -0.000686 & -0.001668 & $0.059488^{* * *}$ \\
\hline$\beta_{1}$ & $0.025146^{* * *}$ & $-0.003799^{* * *}$ & $0.017174^{* * *}$ & $-0.006407^{* * *}$ & $-0.001418^{* * *}$ \\
\hline$\beta_{2}$ & $-0.417980^{* * *}$ & $-0.765549^{* * *}$ & $0.233469^{* * *}$ & $0.393021^{* * *}$ & $-0.683796^{* * *}$ \\
\hline \multirow[t]{2}{*}{$\beta_{3}$} & $-0.002138^{* * *}$ & $-0.011834^{* * *}$ & $-0.004405^{* * *}$ & $-0.004398^{* * *}$ & $-0.013545^{* * *}$ \\
\hline & SSE & TSX & DAX & AORD & BSE \\
\hline$\overline{\alpha_{0}}$ & $0.078490^{* * * *}$ & $0.095450^{* * * *}$ & $0.081691^{* * *}$ & $0.064674^{* * *}$ & $0.114732^{* * *}$ \\
\hline$\alpha_{1}$ & $0.008338^{* * *}$ & $0.002842^{* * *}$ & $0.006848^{* * *}$ & $0.019617^{* * *}$ & $0.004242^{* * *}$ \\
\hline$\alpha_{2}$ & $0.753594^{* * *}$ & $0.405478^{* * *}$ & $0.666130^{* * *}$ & $0.395201^{* * *}$ & $0.580042^{* * *}$ \\
\hline$\lambda_{0}$ & $1.358914^{* * *}$ & $-2.522936^{* * *}$ & $-1.236687^{* * *}$ & $-1.845275^{* * *}$ & $-1.512498^{* *}$ \\
\hline$\lambda_{1}$ & $-0.549423^{* * *}$ & $-0.552330^{* * *}$ & $-0.542548^{* *}$ & $-0.545878^{* * *}$ & $-0.567313^{* * *}$ \\
\hline$\lambda_{2}$ & $0.419093^{* * *}$ & $0.451105^{* * *}$ & $0.429631^{* * *}$ & $0.405188^{* * *}$ & $0.406237^{* * *}$ \\
\hline$\lambda_{3}$ & $1.880591^{* * *}$ & $2.727661^{* * *}$ & $2.198568^{* * *}$ & $3.306989^{* * *}$ & $1.993331^{* * *}$ \\
\hline$\lambda_{4}$ & $-1.970116^{* * *}$ & $-2.804131^{* * *}$ & $-2.279814^{* * *}$ & $-3.355281^{* * *}$ & $-2.082169^{* * *}$ \\
\hline$\beta_{0}$ & $0.021521^{* * *}$ & $0.016240^{* * *}$ & $-7.46 E-05$ & $0.002079^{* * *}$ & $-6.64 E-05$ \\
\hline$\beta_{1}$ & $0.003092^{* * *}$ & $-0.009698^{* * *}$ & $-0.004551^{* * *}$ & $0.011885^{* * *}$ & $-0.000992^{* * *}$ \\
\hline$\beta_{2}$ & $-0.955899^{* * *}$ & $0.043553^{* * *}$ & $0.799342^{* * *}$ & $0.427390^{* * *}$ & $0.779456^{* * *}$ \\
\hline$\beta_{3}$ & $-0.003252^{* * *}$ & $-0.001740^{* * *}$ & $-0.004559^{* * *}$ & $-0.001707^{* * *}$ & $-0.004719^{* * *}$ \\
\hline
\end{tabular}

Note: ${ }^{* * *},{ }^{* *}$, and ${ }^{*}$ in all tables denote that the parameter is significant at $1 \%, 5 \%$, and $10 \%$ level, respectively.

TABLE 7: Results of D-GARCH-M model for both subsamples.

\begin{tabular}{lcccc}
\hline & \multicolumn{2}{c}{ Subsample one } & $\gamma_{1}$ & Subsample two \\
\hline NYSE & $\gamma_{1}$ & $\gamma_{2}$ & $\gamma_{2}$ \\
NASDAQ & $0.640981^{* * *}$ & $-0.679950^{* * *}$ & $0.595190^{* * *}$ & $-0.683966^{* * *}$ \\
N225 & $0.685455^{* * *}$ & $-0.729813^{* * *}$ & $0.618578^{* * *}$ & $-0.766874^{* * *}$ \\
FTSE & $0.629153^{* * *}$ & $-0.692404^{* * *}$ & $0.635881^{* * *}$ & $-0.697001^{* * *}$ \\
HSI & $0.644795^{* * *}$ & $-0.707139^{* * *}$ & $0.561256^{* * *}$ & $-0.660976^{* * *}$ \\
SSE & $0.614571^{* * *}$ & $-0.661842^{* * *}$ & $0.649233^{* * *}$ & $-0.676273^{* * *}$ \\
TSX & $0.622441^{* * *}$ & $-0.623209^{* * *}$ & $0.617179^{* * *}$ & $-0.648040^{* * *}$ \\
DAX & $0.675752^{* * *}$ & $-0.704449^{* * *}$ & $0.604806^{* * *}$ & $-0.679584^{* * *}$ \\
AORD & $0.655910^{* * *}$ & $-0.732814^{* * *}$ & $0.576186^{* * *}$ & $-0.660571^{* * *}$ \\
BSE & $0.648971^{* * *}$ & $-0.697216^{* * *}$ & $0.624139^{* * *}$ & $-0.716930^{* * *}$ \\
\hline
\end{tabular}

Note: ${ }^{* * *},{ }^{* *}$, and ${ }^{*}$ in all tables denote that the parameter is significant at $1 \%, 5 \%$, and $10 \%$ level, respectively.

the last period, the stock price will fall in response to previous unfavorable news and investors will lose in the current period. However, investors may think that the current fallen stock price has almost absorbed the last period's unfavorable news, so it is less likely that the next period's stock price will fall. With the current loss, investors tend to be risk seeking, and their risk aversion will be relatively lower. $\lambda_{3}$ are significantly positive, indicating that investors demand more risk compensation with increasing gains; that is, the more gains the investors get in the current period, the more risk averse the investors will be. $\lambda_{4}$ are significantly negative, indicating the risk compensations that investors demanded reduce with increasing losses; that is, the more the investors lose in the current period, the less risk averse the investors will be.

3.2.4. Risk Preference Has Effect on Conditional Skewness. Combined with above research, it can be found that 
TABLE 8: Results of DR-GARCH-M model for both subsamples.

\begin{tabular}{lcccc}
\hline & \multicolumn{2}{c}{ Subsample one } & \multicolumn{2}{c}{ Subsample two } \\
\hline NYSE & $\gamma_{1}$ & $\gamma_{2}$ & $\gamma_{2}$ \\
NASDAQ & $1.001558^{* * *}$ & $-1.029353^{* * *}$ & $0.522485^{* * *}$ & $-0.570659^{* * *}$ \\
N225 & $0.710845^{* * *}$ & $-0.725153^{* * *}$ & $0.551125^{* * *}$ & $-0.538697^{* * *}$ \\
FTSE & $0.736881^{* * *}$ & $-0.800961^{* * *}$ & $0.504701^{* * *}$ & $-0.643300^{* * *}$ \\
HSI & $0.867442^{* * *}$ & $-0.913827^{* * *}$ & $0.579689^{* * *}$ & $-0.670907^{* * *}$ \\
SSE & $0.859986^{* * *}$ & $-1.0314767^{* * *}$ & $0.411237^{* * *}$ & $-0.529651^{* * *}$ \\
TSX & $0.647975^{* * *}$ & $-0.759942^{* * *}$ & $0.433204^{* * *}$ & $-0.529604^{* * *}$ \\
DAX & $1.204687^{* * *}$ & $-1.224402^{* * *}$ & $0.580805^{* * *}$ & $-0.678481^{* * *}$ \\
AORD & $0.539064^{* * *}$ & $-0.569934^{* * *}$ & $0.516428^{* * *}$ & $-0.579919^{* * *}$ \\
BSE & $1.447118^{* * *}$ & $-1.597704^{* * *}$ & $0.675407^{* * *}$ & $-0.746404^{* * *}$ \\
\hline
\end{tabular}

Note: ${ }^{* * *},{ }^{* *}$, and ${ }^{*}$ in all tables denote that the parameter is significant at $1 \%, 5 \%$, and $10 \%$ level, respectively.

TABLE 9: Results of GARCH-M model for both subsamples.

\begin{tabular}{|c|c|c|c|c|c|}
\hline & $\lambda_{0}$ & $\lambda_{1}$ & $\lambda_{2}$ & $\lambda_{3}$ & $\lambda_{4}$ \\
\hline \multicolumn{6}{|c|}{ Subsample one } \\
\hline NYSE & 0.019299 & $-0.560471^{*}$ & $0.140618^{* * *}$ & $1.537443^{* * *}$ & $-1.485586^{* * *}$ \\
\hline NASDAQ & $-0.190861^{* * *}$ & $0.552694^{* * *}$ & $0.457170^{* * *}$ & $2.509508^{* * *}$ & $-2.553913^{* * *}$ \\
\hline $\mathrm{N} 225$ & $-4.303337^{* * *}$ & $-0.555784^{* * *}$ & $0.454203^{* * *}$ & $2.608714^{* * *}$ & $-2.661776^{* * *}$ \\
\hline FTSE & $-2.097614^{* * *}$ & $-0.549676^{* * *}$ & $0.459551^{* * *}$ & $2.857326^{* * *}$ & $-2.881908^{* * *}$ \\
\hline HSI & $0.813972^{* * *}$ & $-0.556632^{* * *}$ & $0.453012^{* * *}$ & $1.150249^{* * *}$ & $-1.175460^{* * *}$ \\
\hline SSE & $3.055975^{* * *}$ & $-0.558609^{* * *}$ & $0.452607^{* * *}$ & $2.324789^{* * *}$ & $-2.405169^{* * *}$ \\
\hline TSX & $-4.095659^{* * *}$ & $-0.558458^{* * *}$ & $0.447830^{* * *}$ & $4.101495^{* * *}$ & $-4.193618^{* * *}$ \\
\hline DAX & $-1.568814^{* * *}$ & $-0.553748^{* * *}$ & $0.429908^{* * *}$ & $1.708075^{* * *}$ & $-1.767928^{* * *}$ \\
\hline AORD & $-1.600360^{* * *}$ & $-0.544216^{* * *}$ & $0.464784^{* * *}$ & $0.994613^{* * *}$ & $-1.008317^{* * *}$ \\
\hline BSE & $-3.000078^{* * *}$ & $-0.563749^{* * *}$ & $0.425857^{* * *}$ & $2.307102^{* * *}$ & $-2.363432^{* * *}$ \\
\hline \multicolumn{6}{|c|}{ Subsample two } \\
\hline NYSE & $-1.087094^{* * *}$ & $-0.542527^{* * *}$ & $0.444638^{* * *}$ & $1.793444^{* * *}$ & $-1.848726^{* * *}$ \\
\hline NASDAQ & $-2.047090^{* * *}$ & $-0.548294^{* * *}$ & $0.442114^{* * *}$ & $1.889977^{* * *}$ & $-1.958825^{* * *}$ \\
\hline $\mathrm{N} 225$ & $3.699622^{* * *}$ & $-0.560864^{* * *}$ & $0.447874^{* * *}$ & $1.809345^{* * *}$ & $-1.955307^{* * *}$ \\
\hline FTSE & $-1.889732^{* * *}$ & $-0.547451^{* * *}$ & $0.463148^{* * *}$ & $2.148643^{* * *}$ & $-2.201765^{* * *}$ \\
\hline HSI & $-0.651936^{* * *}$ & $-0.564576^{* * *}$ & $0.446703^{* * *}$ & $0.705003^{* * *}$ & $-0.733996^{* * *}$ \\
\hline SSE & -0.605922 & $-0.556074^{* * *}$ & $0.433163^{* * *}$ & $1.593244^{* * *}$ & $-1.688626^{* * *}$ \\
\hline TSX & $-0.570423^{*}$ & $-0.567550^{* * *}$ & $0.457572^{* * *}$ & $2.467647^{* * *}$ & $-2.489784^{* * *}$ \\
\hline DAX & $-2.300593^{* * *}$ & $-0.555535^{* * *}$ & $0.432920^{* * *}$ & $1.843302^{* * *}$ & $-1.914344^{* * *}$ \\
\hline AORD & $-3.133897^{* * *}$ & $-0.557795^{* * *}$ & $0.416543^{* * *}$ & $2.354740^{* * *}$ & $-2.412256^{* * *}$ \\
\hline BSE & $-2.605670^{* * *}$ & $-0.575761^{* * *}$ & $0.386893^{* * *}$ & $0.876803^{* * *}$ & $-0.944603^{* * *}$ \\
\hline
\end{tabular}

Note: ${ }^{* * *},{ }^{* *}$, and ${ }^{*}$ in all tables denote that the parameter is significant at $1 \%, 5 \%$, and $10 \%$ level, respectively.

the GARCHC-M model has effectively captured the characteristics of investors' risk preference which is influenced by the state of gain and loss, the value of return, and also some other time-varying characteristics. In order to examine the effect of investors' risk preference on the conditional skewness, this paper introduces the risk preference $\gamma_{t}$ in GARCHC-M model into the conditional skewness equation to build the GARCHCS-M model. Results of GARCHCS-M model are shown in Table 6.

Table 6 presents the empirical evidence of the effect of investors' risk preference on conditional skewness in GARCHCS-M model. For $\lambda_{0}, \lambda_{1}, \lambda_{2}, \lambda_{3}$, and $\lambda_{4}$ in the risk compensation equation, the results are similar to those in GARCHC-M model. $\lambda_{0}$ in most indexes are significantly negative (SSE and HIS are exceptions, and NYSE's $\lambda_{0}$ is positive but not significant), which suggests that the inherent risk attitude of investors in most stock markets performs risk seeking. $\lambda_{1}$ in all indexes are significantly negative, which demonstrates that if investors were risk aversion in the last period, their current risk tolerance will increase; and if investors were risk seeking in the last period, their current risk tolerance will decrease. Likewise, due to the time-lag action of news, the last period's favorable news $\left(\varepsilon_{t-1}>0\right)$ will cause the current gain, so $\lambda_{2}>0$ indicates the increase 
TABLE 10: Results of GARCHS-M model for both subsamples.

\begin{tabular}{|c|c|c|c|c|c|c|}
\hline & $\lambda_{0}$ & $\lambda_{1}$ & $\lambda_{2}$ & $\lambda_{3}$ & $\lambda_{4}$ & $\beta_{3}$ \\
\hline \multicolumn{7}{|c|}{ Subsample one } \\
\hline NYSE & 0.149401 & $-0.548242^{* * *}$ & $0.431393^{* * *}$ & $3.672784^{* * *}$ & $-3.866663^{* * *}$ & $-0.000130^{* * *}$ \\
\hline NASDAQ & $-0.513311^{* * *}$ & $-0.548874^{* * *}$ & $0.459606^{* * *}$ & $2.710596^{* * *}$ & $-2.755633^{* * *}$ & $-0.001513^{* * *}$ \\
\hline N225 & $-3.777040^{* * *}$ & $-0.556352^{* * *}$ & $0.453421^{* * *}$ & $2.644557^{* * *}$ & $-2.681098^{* * *}$ & $-0.000891^{* * *}$ \\
\hline FTSE & $-0.921792^{*}$ & $-0.553122^{* * *}$ & $0.373123^{* * *}$ & $2.788999^{* * *}$ & $-2.825051^{* * *}$ & $-0.002944^{* * *}$ \\
\hline HSI & $2.475027^{* *}$ & $-0.561807^{* * *}$ & $0.424600^{* * *}$ & $3.151613^{* * *}$ & $-3.205647^{* * *}$ & $-0.004062^{* * *}$ \\
\hline SSE & $1.391548^{* * *}$ & $-0.601986^{* * *}$ & $0.404642^{* * *}$ & $1.884679^{* * *}$ & $-1.997258^{* * *}$ & $-0.002907^{* * *}$ \\
\hline TSX & $-4.761000^{* * *}$ & $-0.552547^{* * *}$ & $0.458116^{* * *}$ & $4.451923^{* * *}$ & $-4.543090^{* * *}$ & $-0.000454^{* * *}$ \\
\hline DAX & $-1.425049^{* * *}$ & $-0.545360^{* * *}$ & $0.403189^{* * *}$ & $2.241518^{* * *}$ & $-2.359356^{* * *}$ & $-0.007290^{* * *}$ \\
\hline AORD & $-5.386529^{* * *}$ & $-0.543488^{* * *}$ & $0.411663^{* * *}$ & $5.148688^{* * *}$ & $-5.155793^{* * *}$ & $-0.000302^{* * *}$ \\
\hline BSE & $-1.423630^{* *}$ & $-0.578691^{* * *}$ & $0.375985^{* * *}$ & $2.328986^{* * *}$ & $-2.373751^{* * *}$ & $-0.004478^{* * *}$ \\
\hline \multicolumn{7}{|c|}{ Subsample two } \\
\hline NYSE & $-1.520766^{* *}$ & $-0.526001^{* * *}$ & $0.460741^{* * *}$ & $2.079199^{* * *}$ & $-2.156131^{* * *}$ & $-0.002908^{* * *}$ \\
\hline NASDAQ & $-2.059548^{* * *}$ & $-0.560921^{* * *}$ & $0.438179^{* * *}$ & $2.082888^{* * *}$ & $-2.124802^{* * *}$ & $-0.007101^{* * *}$ \\
\hline N225 & $2.280618^{* * *}$ & $-0.558477^{* * *}$ & $0.398786^{* * *}$ & $1.755023^{* * *}$ & $-1.855310^{* * *}$ & $-0.016086^{* * *}$ \\
\hline FTSE & $-2.211826^{* * *}$ & $-0.592518^{* * *}$ & $0.335528^{* * *}$ & $1.900084^{* * *}$ & $-1.966627^{* * *}$ & $-0.015200^{* * *}$ \\
\hline HSI & $-0.877987^{*}$ & $-0.546284^{* * *}$ & $0.445602^{* * *}$ & $1.604401^{* * *}$ & $-1.671164^{* * *}$ & $-0.00813^{* * *}$ \\
\hline SSE & $-2.552083^{* * *}$ & $-0.549725^{* * *}$ & $0.432000^{* * *}$ & $1.761072^{* * *}$ & $-1.844075^{* * *}$ & $-0.007611^{* * *}$ \\
\hline TSX & -0.655421 & $-0.570514^{* * *}$ & $0.447033^{* * *}$ & $2.531141^{* * *}$ & $-2.560608^{* * *}$ & $-0.002375^{* * *}$ \\
\hline DAX & $-2.351308^{* * *}$ & $-0.555709^{* * *}$ & $0.350298^{* * *}$ & $1.851416^{* * *}$ & $-1.815590^{* * *}$ & $-0.022803^{* * *}$ \\
\hline AORD & $-0.481914^{* *}$ & $-0.605378^{* * *}$ & $0.323437^{* * *}$ & $2.042283^{* * *}$ & $-2.045983^{* * *}$ & $-0.029672^{* * *}$ \\
\hline BSE & $-1.743111^{* * *}$ & $-0.548526^{* * *}$ & $0.397695^{* * *}$ & $1.649966^{* * *}$ & $-1.739665^{* * *}$ & $-0.003711^{* * *}$ \\
\hline
\end{tabular}

Note: ${ }^{* * *},{ }^{* *}$, and ${ }^{*}$ in all tables denote that the parameter is significant at $1 \%, 5 \%$, and $10 \%$ level, respectively.

in investors risk aversion, while the last period's unfavorable news $\left(\varepsilon_{t-1}<0\right)$ will give rise to the current loss which makes investor less risk averse when there exist $\lambda_{2}>0$. In all indees, there are $\lambda_{3}>0$ and $\lambda_{4}<0$, which are the same with previous study. In other words, the degree of investors risk aversion rises with the increasing current gain while reduce with the increasing current loss.

The effect of investors' risk preference on skewness, denoted by coefficient $\beta_{3}$, is significant and mostly negative in most indexes (except BSE), which proves that investors' risk preference influences the return skewness. The higher the degree of investors' risk aversion is, the smaller the conditional skewness is. This is due to the fact that when most investors on the market show risk aversion $\left(\gamma_{t}<0\right)$, they will be more cautious about their investment decisions, thereby depressing their demand for stocks, which increases the falling possibility of stock price and lowers the skewness of the return distribution. On the other hand, if investors' aggregate risk attitude tends to be risk seeking $\left(\gamma_{t}>0\right)$, the conditional skewness will increase; this is because risk seeking investors tend to be adventurous, which usually accelerates the need for stock on markets leading more possibly to increases of stock price, thus increasing the skewness.

\section{Robustness Test}

We divide the whole sample into two subsamples with the same length to test the robustness of our findings. The time span of subsample one is from March 1, 2002, to March 30,
2007, while that of sub-sample two is from March 2007 to March 30, 2012. The D-GARCH-M model, the DR-GARCH$\mathrm{M}$ model, the GACRCHC-M model, and the GARCHCS-M model are estimated again by using those two sub-samples. And the results are shown in Tables 7, 8, 9, and 10, respectively.

From the parameter estimated by models in all tables, we find that the results are generally consistent with those reported in previous part of this paper. Table 7 presents the result of D-GARCH-M model, it can be seen that for both sub-samples there exist $\gamma_{1}>0$ and $\gamma_{2}<0$. This indicates that investors are risk averse with gains and risk seeking with losses, which is consistent with the above finding.

Table 8 displays the result of DR-GARCH-M model and also presents $\gamma_{1}>0$ and $\gamma_{2}<0$ in both samples. It also proves that investors are risk averse for gains and risk seeking for losses. Moreover, we can also conclude that the degree of investors' risk aversion for risk rises with the increasing gains and that of risk seeking also enhances with the increasing losses. Namely, the degree of investors' risk aversion and risk seeking is positively related to the size of obtained gains and losses, respectively.

Table 9 presents the results of the GARCHC-M model investigating other time-varying characteristics of investors' risk preference. Most $\lambda_{0}$ in both sub-samples are significantly negative, which suggests that investors' inherent risk preference is risk seeking; $\lambda_{1}$ are significantly negative, which denotes that investors' current period's risk preference is affected by their last period's attitude to risk. If investors were risk averse in the last period, their current risk tolerance 
will increase; and when investors were risk seeking in the last period, their current risk tolerance will decrease. And $\lambda_{2}$ are significantly positive, which also manifest the effect of last period's disturbance on risk preference. Parameters $\lambda_{3}$ are significantly greater than zero and $\lambda_{4}$ are significantly less than zero, which mean that the extent of investors' risk aversion will improve with the increasing gains and will be lowered with the increasing losses.

The result of the GARCHCS-M model in Table 10 proves that investors' risk preference has significantly negative effect on the conditional skewness. That is to say, the return skewness will reduce if the investors generally are risk aversion; and if investors generally are risk seeking, the skewness will increase.

From the above analysis, we can conclude that the choice of sample will not produce great effect on the effectiveness of our models and our findings in this paper are consistent.

\section{Conclusion}

This paper firstly makes a full depiction on the time-varying characteristics of investors' risk preference at market level based on extended GARCH-M models (the D-GARCHM model, DR-GARCH-M model, GARCHC-M model, and GARCHCS-M model). Then, it further studies how investors' risk preference influences the return skewness. Firstly, we find that investor's risk preference changes with states of gain and loss, manifesting risk aversion with gains and risk seeking with losses, which effectively explains the inconsistency riskreturn relationship. Secondly, investors' risk preference is also influenced by the magnitude of return; the degree of investor's risk aversion positively related to the value of gains; and that of risk seeking positively related to the value of losses. Thirdly, when considering other factors that influence investors' risk preference, we find that people's inherent risk preference overall is risk seeking, and the current risk preference is influenced by last period's risk preference and other disturbance. What is more, the extent of investors' risk aversion improves with increasing gains and reduces with increasing losses. With further study, we also find that investors' risk preference influences the conditional skewness. Specifically, when investors in the market show risk averse on the whole, the skewness of return distribution will reduce; when investors overall show risk seeking, the skewness of return distribution will increase, which also further proves the conclusion of negative correlation between the risk compensate coefficient and skewness in the study of Wen and Yang [22].

\section{Conflict of Interests}

The authors declare that there is no conflict of interests regarding the publication of this paper.

\section{Acknowledgment}

This work was supported in part by the Natural Science Foundation of China (nos. 71171024, 71371195, and 71221061).

\section{References}

[1] D. Kahneman and A. Tversky, "Prospect theory: an analysis of decision under risk," Econometrica, vol. 47, no. 2, pp. 263-291, 1979.

[2] D. Laughhunn and J. W. Payne, "The impact of sunk outcomes on risky choice behavior," Canadian Journal of Operations Research and Information Processing, vol. 22, no. 2, pp. 155-181, 1984.

[3] B. Fernandes and J. Luiz, "Risk Taking In Financial Markets: A Behavioral Perspective," 2007.

[4] M.-S. Haigh and J.-A. List, "Do professional traders exhibit myopic loss aversion? an experimental analysis," Journal of Finance, vol. 60, no. 1, pp. 523-534, 2005.

[5] M. Abdellaoui, H. Bleichrodt, and C. Paraschiv, "Loss aversion under prospect theory: a parameter-free measurement," Management Science, vol. 53, no. 10, pp. 1659-1674, 2007.

[6] H.-M. Anderson, K. Nam, and F. Vahid, "An asymmetric nonlinear smooth-transition GARCH models," Nonlinear Time Series Analysis of Economic and Finance Data, vol. 1, pp. 191-207, 1999.

[7] R.-H. Thaler and E.-J. Johnson, "Gambling with the house money and trying to break even: the effects of prior outcomes on risky choice," Management Science, vol. 36, no. 6, pp. 643660, 1990.

[8] N. Barberis, M. Huang, and T. Santos, "Prospect theory and asset prices," Quarterly Journal of Economics, vol. 116, no. 1, pp. $1-53,2001$.

[9] N. Barberis and W. Xiong, "What drives the disposition effect? An analysis of a long-standing preference-based explanation," Journal of Finance, vol. 64, no. 2, pp. 751-784, 2009.

[10] M.-K. Brunnermeier and S. Nagel, "Do wealth fluctuations generate time-varying risk aversion? Micro-evidence on individuals' asset allocation," American Economic Review, vol. 98, no. 3, pp. 713-736, 2008.

[11] R. Chou, R.-F. Engle, and A. Kane, "Measuring risk aversion from excess returns on a stock index," Journal of Econometrics, vol. 52, no. 1-2, pp. 201-224, 1992.

[12] G. Li, “Time-varying risk aversion and asset prices," Journal of Banking and Finance, vol. 31, no. 1, pp. 243-257, 2007.

[13] J. Cotter and J. Hanly, "Time-varying risk aversion: an application to energy hedging," Energy Economics, vol. 32, no. 2, pp. 432-441, 2010.

[14] A.-A. Christie, "The stochastic behavior of common stock variances. Value, leverage and interest rate effects," Journal of Financial Economics, vol. 10, no. 4, pp. 407-432, 1982.

[15] K.-R. French, G.-W. Schwert, and R.-F. Stambaugh, "Expected stock returns and volatility," Journal of Financial Economics, vol. 19, no. 1, pp. 3-29, 1987.

[16] A. Ekholm and D. Pasternack, "The negative news threshold-an explanation for negative skewness in stock returns," European Journal of Finance, vol. 11, no. 6, pp. 511-529, 2005.

[17] K.-H. Bae, C. Lim, and K.-C.-J. John Wei, "Corporate governance and conditional skewness in the world's stock markets," Journal of Business, vol. 79, no. 6, pp. 2999-3028, 2006.

[18] C.-R. Harvey and A. Siddique, "Conditional skewness in asset pricing tests," Journal of Finance, vol. 55, no. 3, pp. 1263-1295, 2000.

[19] G. Bakshi, N. Kapadia, and D. Madan, "Stock return characteristics, Skew laws, and the differential pricing of individual equity options," Review of Financial Studies, vol. 16, no. 1, pp. 101-143, 2003. 
[20] F. Wen, D. Huang, Q. Lan, and X. Yang, "Numerical simulation for influence of overconfidence and regret aversion on return distribution," System Engineering Theory and Practice, vol. 27, no. 7, pp. 10-18, 2007.

[21] T. Post, P.-V. Vliet, and H. Levy, "Risk aversion and skewness preference," Journal of Banking and Finance, vol. 32, no. 7, pp. 1178-1187, 2008.

[22] F. Wen and X. Yang, "Skewness of return distribution and coefficient of risk premium," Journal of Systems Science and Complexity, vol. 22, no. 3, pp. 360-371, 2009.

[23] E. Ghysels, P. Santa-Clara, and R. Valkanov, "There is a riskreturn trade-off after all," Journal of Financial Economics, vol. 76, no. 3, pp. 509-548, 2005.

[24] H. Guo and R.-F. Whitelaw, "Uncovering the risk-return relation in the stock market," Journal of Finance, vol. 61, no. 3, pp. 1433-1463, 2006.

[25] S. Das and N. Sarkar, "Is the relative risk aversion parameter constant over time? A multi-country study," Empirical Economics, vol. 38, no. 3, pp. 605-617, 2010.

[26] M.-V. Brandt and Q. Kang, "On the relationship between the conditional mean and volatility of stock returns: a latent VAR approach," Journal of Financial Economics, vol. 72, no. 2, pp. 217257, 2004.

[27] A. Ang, R. J. Hodrick, Y. Xing, and X. Zhang, “The cross-section of volatility and expected returns," Journal of Finance, vol. 61, no. 1, pp. 259-299, 2006.

[28] T.-G. Bali, K. O. Demirtas, and H. Levy, "Is there an intertemporal relation between downside risk and expected returns?" Journal of Financial and Quantitative Analysis, vol. 44, no. 4, pp. 883-909, 2009.

[29] R.-T. Baillie and R.-P. DeGennaro, "Stock returns and volatility," Journal of Financial and Quantitative Analysis, vol. 25, no. 2, pp. 203-214, 1990.

[30] J.-Y. Campbell and L. Hentschel, "No news is good news. An asymmetric model of changing volatility in stock returns," Journal of Financial Economics, vol. 31, no. 3, pp. 281-318, 1992.

[31] A. Goyal and P. Santa-Clara, "Idiosyncratic Risk Matters!", Journal of Finance, vol. 58, no. 3, pp. 975-1007, 2003.

[32] M. Lanne and P. Saikkonen, "Why is it so difficult to uncover the risk-return tradeoff in stock returns?" Economics Letters, vol. 92, no. 1, pp. 118-125, 2006.

[33] M. Lanne and J. Luoto, "Robustness of the risk-return relationship in the U.S. stock market," Finance Research Letters, vol. 5, no. 2, pp. 118-127, 2008.

[34] A. Kanas, "Modelling the risk-return relation for the S\&P 100: the role of VIX," Economic Modelling, vol. 29, no. 3, pp. 795-809, 2012.

[35] B. J. Christensen, M. Ø. Nielsen, and J. Zhu, "The impact of financial crises on the risk-return tradeoff and the leverage effect," CREATES Research Paper, 2012.

[36] J.-R. Anderson, "Verbatim and propositional representation of sentences in immediate and long-term memory," Journal of Verbal Learning and Verbal Behavior, vol. 13, no. 2, pp. 149-162, 1974.

[37] J.-M. Mandler and G.-H. Ritchey, "Long-term memory for pictures," Journal of Experimental Psychology, vol. 3, no. 4, pp. 386-396, 1977.

[38] B. Lev, "Industry averages as targets for financial ratios," Journal of Accounting Research, vol. 7, no. 2, pp. 290-299, 1969.

[39] T.-J. Frecka and C.-F. Lee, "Generalized financial ratio adjustment processes and their implications," Journal of Ccounting Research, vol. 21, no. 1, pp. 308-316, 1983.
[40] M. Grinblatt and B. Han, "Prospect theory, mental accounting, and momentum," Journal of Financial Economics, vol. 78, no. 2, pp. 311-339, 2005.

[41] D. Prelec and G. Loewenstein, "Decision making over time and under uncertainty: a common approach," Management Science, vol. 37, no. 7, pp. 770-786, 1991.

[42] A. Hopfensitz, "Previous outcomes and reference dependence: a meta study of repeated investment tasks with and without restricted feedback," MPRA Working Paper 16096, 2009.

[43] P. O'Connell and M. Teo, "Institutional investors, past performance, and dynamic loss aversion," Journal of Financial and Quantitative Analysis, vol. 44, no. 1, pp. 155-188, 2009.

[44] D. Genesove and C. Mayer, "Loss aversion and seller behavior: evidence from the housing market," Quarterly Journal of Economics, vol. 116, no. 4, pp. 1233-1260, 2001.

[45] Á. León, G. Rubio, and G. Serna, "Autoregresive conditional volatility, skewness and kurtosis," Quarterly Review of Economics and Finance, vol. 45, no. 4-5, pp. 599-618, 2005.

[46] Q.-F. Xu, Financial Higher Order Moment of Risk Identification and Control, Tsinghua University Press, Beijing, China, 2007. 


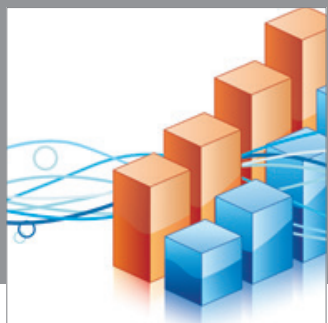

Advances in

Operations Research

mansans

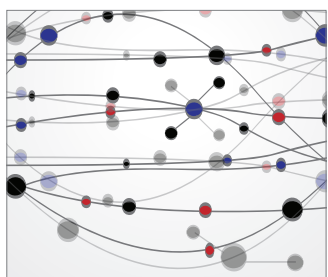

The Scientific World Journal
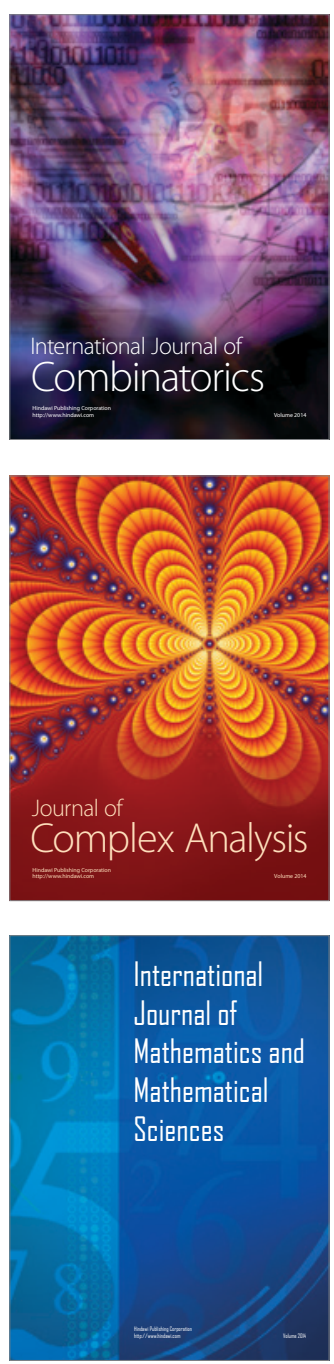
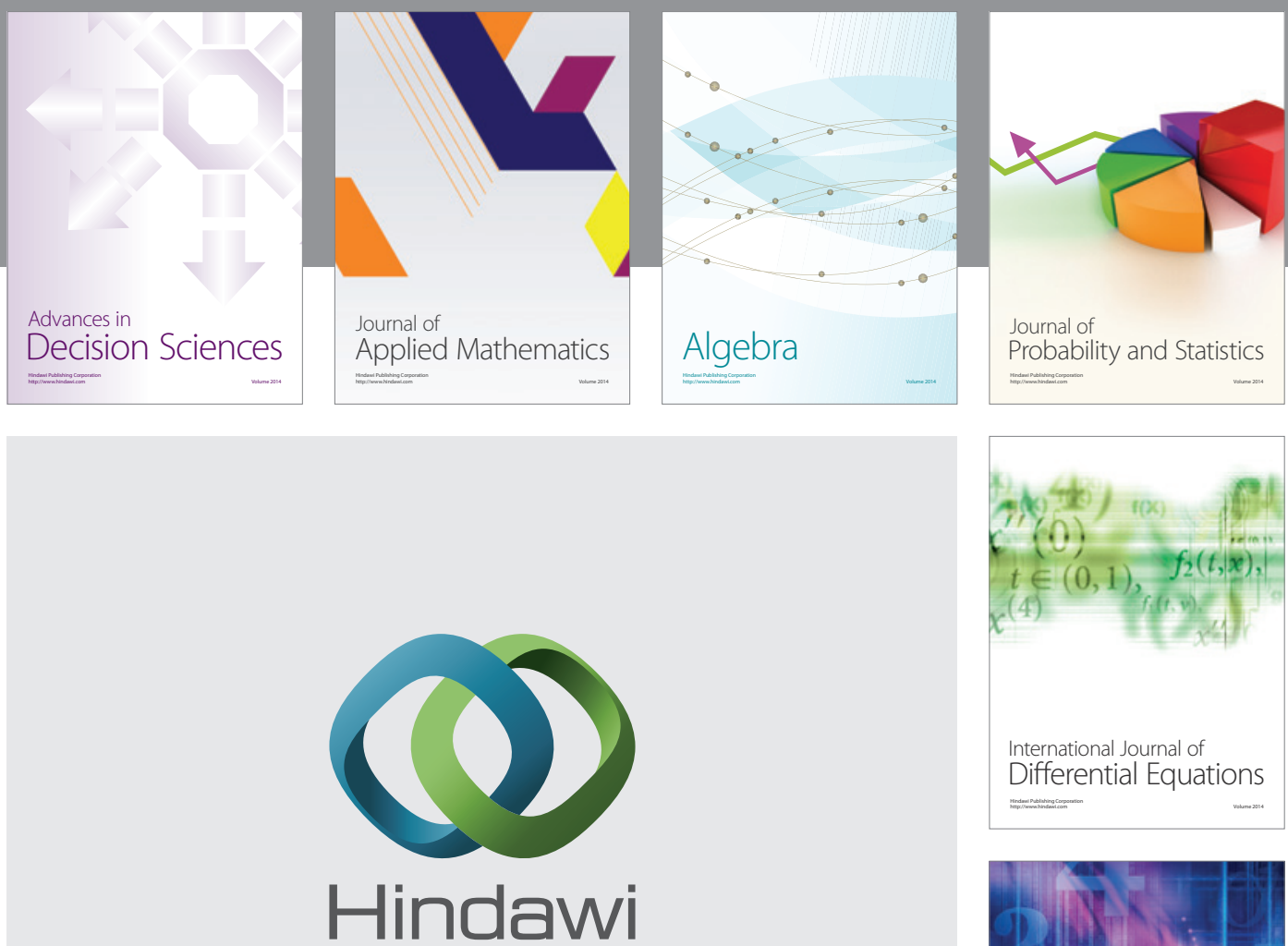

Submit your manuscripts at http://www.hindawi.com
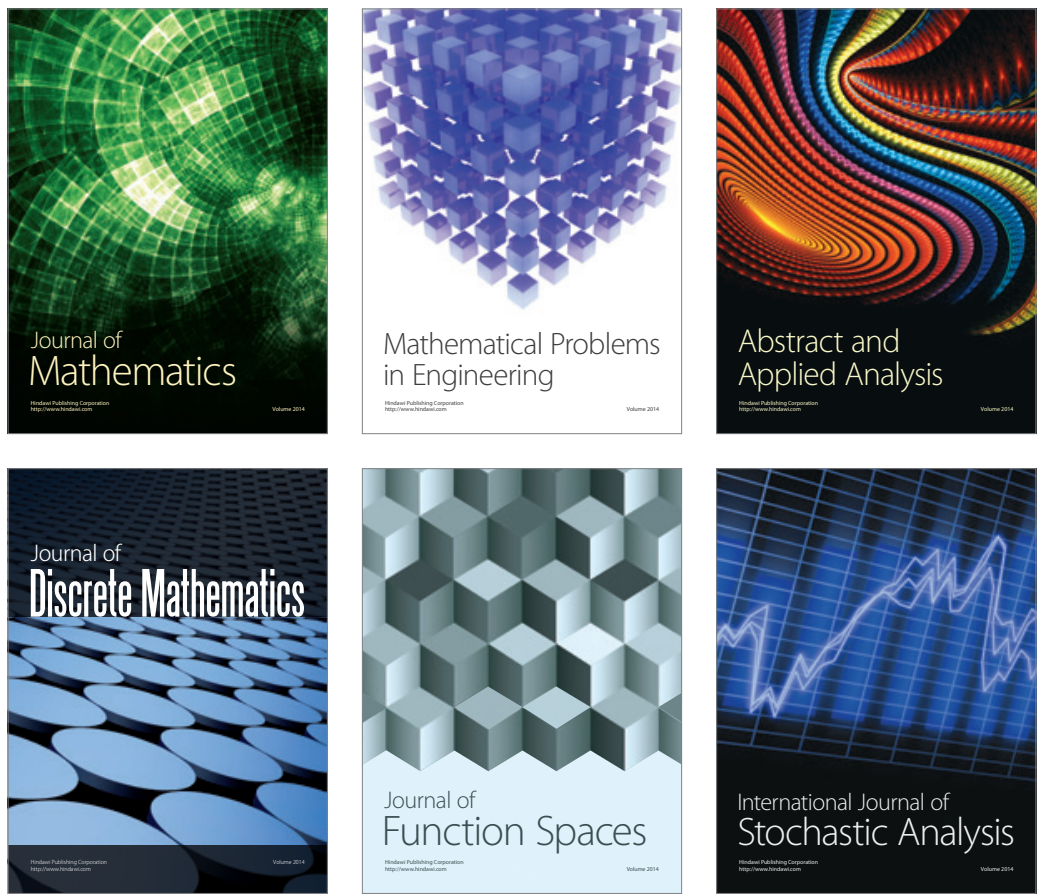

Journal of

Function Spaces

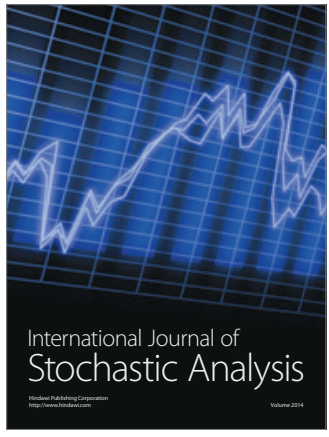

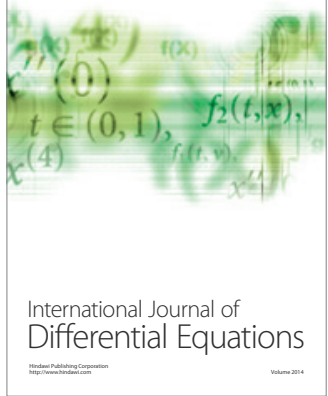
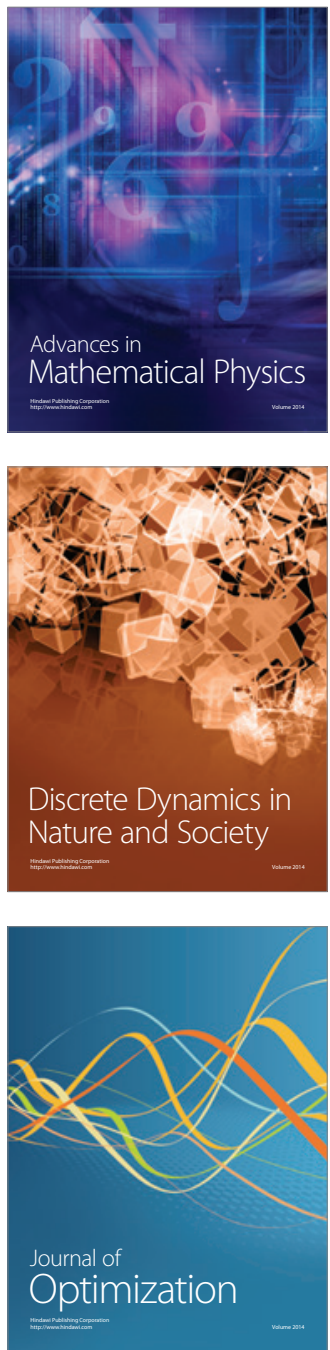